\title{
A STUDY OF HUMAN LIVER BILE AFTER RELEASE OF COMMON DUCT OBSTRUCTION
}

\author{
By I. S. RAVDIN, C. G. JOHNSTON,1 C. RIEGEL AND S. L. WRIGHT 2
}

(From the Laboratory of Surgical Research and the John Herr Musser Department of Research Medicine, University of Pennsylvania, Philadelphia)

(Received for publication February 16, 1933)

For some years it has been a common practice for surgeons to insert a drainage tube into the common duct after choledochotomy for calculi, stricture, chronic pancreatitis, suppuration or even malignancy. Whether such drainage is always necessary if the obstruction has been relieved, has often been questioned by those who believe that primary closure of the duct can often be done without danger to the patient, especially where the obstruction is not complete. There appears to be no general agreement as to how long the drainage should be continued in the various conditions, nor is there any general unanimity of opinion as to whether prolonged biliary drainage is dangerous.

Wangensteen (1) has called attention to the effect on patients of prolonged biliary drainage and Walters and Parham (2) have commented on the development of cholerrhagia as an unfavorable sequel to surgical drainage of the biliary tract. Two more recent papers by Walters, Greene and Frederickson (3) and Greene, Walters and Fredrickson (4) have again emphasized the necessity of a careful study of the entire problem in an effort to improve surgical end-results in cases of the type under discussion.

During a period when we were studying the anion-cation concentrations of human gallbladder bile removed from normal and diseased gallbladders during life, we obtained and studied the bile from 18 patients who had obstruction of the common duct from calculi, stricture, malignancy or infection, and who lived at least five days after operation. Four died after this period and 14 recovered. The specimens were collected daily, measured, and analyzed for certain of their constituents. The drainage was continued for a variable period, the longest being 191 days.

\section{METHOD}

In nearly every instance the bile was obtained by the introduction at operation of a soft rubber " $T$ " tube which was later connected to a flask

1 Harriet M. Frazier Fellow in Surgical Research.

2 Robert M. Girvin Fellow in Research Medicine. 
at the side of the bed. The volume of the bile collected each day was read to the nearest 5 or $10 \mathrm{cc}$. mark.

The methods used for the determination of calcium, bile salts, chloride, total base, and $\mathrm{CO}_{2}$, have been reported in previous papers (5) (6) (7) (8).

\section{AMOUNT OF BILE}

It was often impossible to determine what part of the total biliary excretion we were obtaining from the " $T$ " tube, since for the first 24 to 48 hours there was some bile lost into the dressings from around the tube, and also because when the obstruction was completely removed a portion of the liver bile passed into the duodenum.

In the same patient there were marked variations in the bile collected from day to day. Whether this was an expression of an increased or decreased formation of bile, we could not as a rule determine. In certain instances, however, this may have been the case, since no bile could be demonstrated in the feces for several days prior to, or subsequent to, the time during which we believed we were obtaining the total output of bile. The minimum amount obtained under such conditions was $50 \mathrm{cc}$. and the maximum amount $1530 \mathrm{cc}$. per day.

For the first 5 days after operation the average amount of bile collected differed considerably in the patients who died as compared with that from the patients who recovered. Of the four patients who died after the fifth day, the average bile flow per day was $152 \mathrm{cc}$. (maximum $1785 \mathrm{cc}$. for 5 days; minimum $250 \mathrm{cc}$.), while in the 14 patients who survived operation, the average bile flow per day for the first 5 days was $374 \mathrm{cc}$. (maximum $3225 \mathrm{cc}$. for 5 days; minimum $1460 \mathrm{cc}$.). In only one of the patients who died did the total amount collected in the first five days equal the amount obtained from any of the recovered cases in a similar period.

In the one patient whose tube remained in position for 191 days the minimum drainage in a 24 hour period was $150 \mathrm{cc}$. and the maximum 1030 cc. For approximately 170 days the " $\mathrm{T}$ " tube was clamped at its exterior during the entire day and was opened only during the period when he slept. The patient was on a carefully regulated low fat, high carbohydrate diet and showed no evidence of harm from the prolonged drainage. Indeed he gained in weight and improved considerably in his general health.

\section{BILE SALTS}

We had previously observed that when cholangitis occurred in dogs with biliary fistulae, the bile salts, as demonstrated by the Gregory-Pascoe method (9), rapidly disappeared, and in a previous paper (8) we reported that it was frequently impossible to demonstrate their presence in bile from a badly diseased gallbladder.

In every instance in which liver bile was obtained from patients with 
complete common duct obstruction of a week or more duration, bile salts, as demonstrated by the Gregory-Pascoe (9) reaction, were not present. Frequently a number of days passed after the release of the obstruction before bile salts reappeared in the liver bile. The interval between release of the obstruction and the appearance of bile salts in the liver bile appeared to be roughly proportional to the degree and duration of the obstruction, and to the degree of cholangitis associated with the obstruction. In a number of instances (Table $\mathrm{I}$ ) the " $\mathrm{T}$ " tube was removed before bile salts had reappeared in the bile.

TABLE I

The time interval from release of a complete obstruction of the common bile duct to the appearance of bile salts in the bile

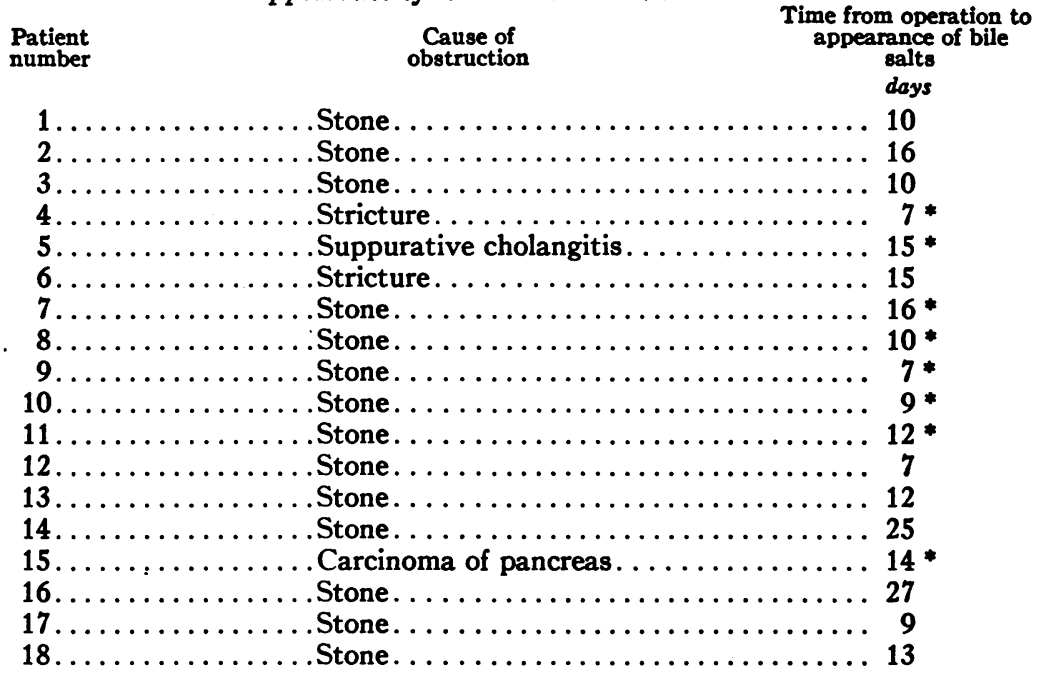

* No further specimens obtainable, negative Gregory-Pascoe reaction in last specimen obtained.

The highest bile salt concentration obtained in any of these cases was $32 \mathrm{~m}$.Eq. per liter, 16 days after the release of an obstruction of five days duration due to a stone. This is within the range of the mean concentration of bile salts in the normal hepatic bile of the dog (8). We have never been fortunate enough to obtain hepatic bile from a human subject in whom there was no evidence of biliary tract disease so that we cannot state what the concentration of bile salts would be in such cases. On the whole, however, our data for bile salts in these patients are considerably below the concentration of bile salts in the hepatic bile from normal dogs, which varied from 16 to $66 \mathrm{~m}$. Eq. per liter (8).

\section{BASE}

In the 18 cases, determinations of total base were made in 22 instances. The highest total base was $181 \mathrm{~m} . \mathrm{Eq}$. per liter and the lowest 121 , with a 
mean of 158.6, the median being 159. In the dog's normal hepatic bile we had previously determined that the total base was usually higher than it was in serum (8). While this was true in occasional instances after drainage in the human cases, the total base was at times below that of serum for some days after the release of the obstruction. The mean concentration in the first 5 days was 157 , while for the second 5 days of drainage it was $161 \mathrm{~m}$. Eq. per liter.

Calcium determinations were made on 217 specimens of bile collected. The concentrations varied from $1.1 \mathrm{~m}$.Eq. per liter to 10.2, with a mean concentration of 4.4. While in the normal dog's hepatic bile the calcium concentration was in the majority of instances above that of the dog's serum, in the human cases the calcium concentration of the hepatic bile was often well below that of human serum. The bile collected from all cases in the first 24 hours after the release of the obstruction had a mean concentration of calcium of $3.6 \mathrm{~m}$.Eq. per liter, the lowest concentration being 1.6 and the highest 5.4, which would not indicate any accumulation of calcium in stasis bile.

There appeared to be no inverse correlation between calcium concentration and total amount of bile collected in any given period. Indeed, it was common to find a higher concentration of calcium associated with a greater output of bile. Generally there was a tendency for the concentration to increase as the condition of the patient improved; but this finding was not a constant one, since two of the patients who recovered maintained a very low concentration throughout the study. One of these varied constantly between 1.1 and $3.0 \mathrm{~m}$.Eq. per liter over a 25 day period, and the other had a higher calcium concentration at the beginning than at the end of the study (Table II). As a rule, however, the patients who survived had calcium concentrations (Table III) of the liver bile, at the time of removal of the tube, at or above the serum concentration of calcium, while those who died had a lower concentration in the last specimen obtained. In the 14 patients who recovered, the mean concentration was $5.3 \mathrm{~m}$.Eq. per liter, while in the 4 patients who died, the mean concentration of calcium was 2.9. Our findings as to the daily variations in the calcium concentrations of hepatic bile agree with the data we have previously reported for the dog (8). We have found the calcium concentration of "white bile" in the human subject to be low, which agrees with the findings of Drury (10) on "white bile" from the dog.

There was no constant correlation between the serum calcium concentration and the calcium concentration of the collected bile. In those instances where the calcium concentration of the bile was very low, 1 to 2 m.Eq. per liter, the serum calcium was normal. It would appear from this that calcium was being held back by the damaged liver. 
I. S. RAVDIN, C. G. JOHNSTON, C. RIEGEL AND S. L. WRIGHT 663






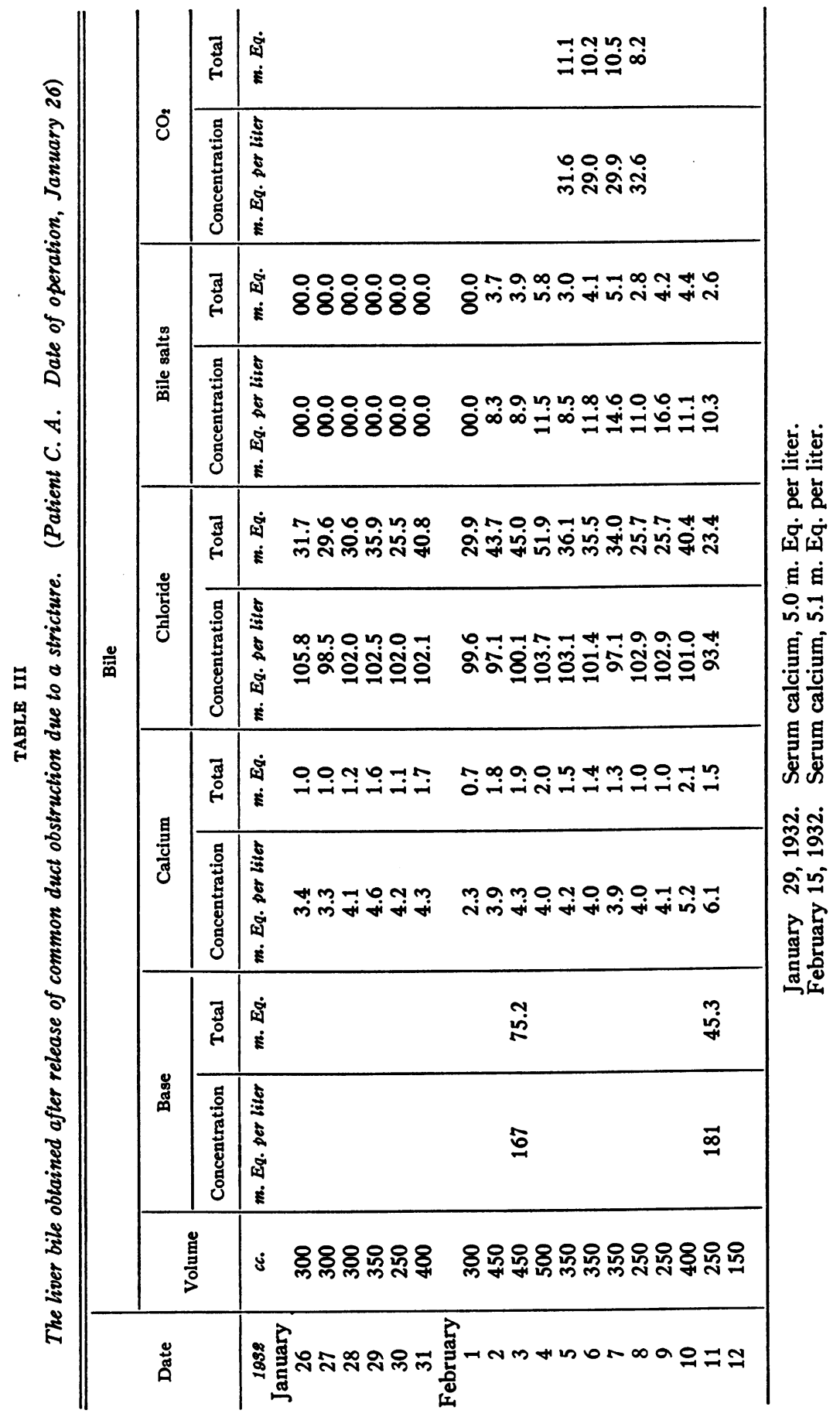




\section{CHLORIDE}

Chloride determinations were made on 217 specimens of the collected bile. The mean chloride concentration was $104.4 \mathrm{~m}$.Eq. per liter. As a rule, the chloride values were slightly higher immediately after release of the obstruction than at the time the drainage tube was removed. In the 13 cases in which it was possible to obtain bile for ten days or more, the mean chloride concentration for the first 5 days was $111.2 \mathrm{~m}$.Eq. per liter while the mean chloride concentration for the last 5 days of drainage was 97.8.

Of the 4 cases which died the chloride concentration was usually higher than any level attained in the cases which lived; and decidedly higher (mean $122.3 \mathrm{~m} . \mathrm{Eq}$. per liter) than the mean chloride concentration of the specimens examined from all the cases in this study.

The chloride concentration in these specimens was nearly always higher than the chloride concentration of the normal dog's hepatic bile, but compares favorably with the data we have obtained from the hepatic bile of dogs that had developed cholangitis.

\section{TOTAL $\mathrm{CO}_{2}$}

Determinations of the total $\mathrm{CO}_{2}$ were made on a few of the specimens of bile. The mean $\mathrm{CO}_{2}$ concentration was $22.7 \mathrm{~m}$.Eq. per liter, with the median at 24.4. The high total $\mathrm{CO}_{2}$ frequently encountered in bile from the diseased gallbladder was not found in the hepatic bile from the cases here reported, although there existed in numerous instances marked hepatitis and varying degrees of cholangitis. The concentrations noted in the hepatic bile from the human subject were often lower than the concentrations found in normal dog's hepatic bile.

\section{TOTAL SALT AND FLUID LOST}

Of considerable interest in cases of the type under discussion is the fluid and salt loss during the period of external drainage. We have selected three typical patients, two who recovered, and one who died, as examples.

In the first patient, liver bile was obtained over a period of 27 days. The patient had a stone in the common duct. His history in brief was as follows: E. S., male, age 45. Admitted to the Service of Dr. Ravdin at the Hospital of the University of Pennsylvania November 9, 1931, discharged December 15, 1931.

Since 1926 he had had repeated attacks of pain in the right upper abdomen and right scapular region. The attacks were associated with vomiting but not with jaundice. On November 4, 1931, he had a mild attack and two more attacks on the 5th. On the 8th he noticed that he was yellow. On November 9 he had another severe attack and was then sent to the hospital. Fatty foods had been poorly tolerated. He had had no chills during his illness.

On admission the temperature was 97.3 , pulse 96 , respiration. 24 . The blood urea nitrogen was $24 \mathrm{mgm}$. per $100 \mathrm{cc}$. The urine contained bilirubin but was otherwise negative. The bleeding time was 1.5 minutes and the coagulation time 
by the Lee-White method was 8.5 minutes. The van den Bergh was direct positive, indirect 9.5 units. The icteric index was 100 . The serum calcium was $10.6 \mathrm{mgm}$. per $100 \mathrm{cc}$. and the serum phosphates $4.3 \mathrm{mgm}$. per $100 \mathrm{cc}$.

After preliminary preparation with 10 per cent glucose for three days he was operated on under novocain-spinal anesthesia. A single mulberry shaped stone was removed from the common duct after which a " $\mathrm{T}$ " tube was inserted for external drainage. The gallbladder was then opened and found to contain white bile and six stones of a type similar to that found in the common duct. These were removed after which a rubber tube was inserted and the gallbladder closed around it. The patient stood the operation well and on leaving the operating room his pulse was 110 and blood pressure 130/70. The data from the bile collected from this patient are given in Table II. The total output of base, calcium, chloride and bile salts bears a close relation to the total bile drainage for a given period. This relationship is, however, not a linear one for the entire period in any given patient since there is a tendency for daily variation in the concentration of the individual constituents as the condition of the patient improves after release of the obstruction.

The second patient's bile was obtained for 18 days. C. A., female, age 40 . Admitted to the Service of Dr. Eliason at the Hospital of the University of Pennsylvania, January 24, 1932, and discharged February 18, 1932.

In 1909 the patient began to have pain in the upper right quadrant which came on about half an hour after eating fatty foods. Shortly after this she noticed that she frequently became jaundiced after a severe attack of pain, nausea and vomiting. The attacks came on about twice a month. In 1922 she was operated on and the gallbladder was removed. Following this she was symptom-free for 3 years. In July 1931 she noticed marked dyspnea on exertion and during an attack. Her last attack began on January 20, four days before she was admitted to the hospital.

Her weight had varied from 180 pounds in 1912 to 210 pounds on admission.

On admission the temperature was 99.1 , pulse 100 , respiration 24 . The blood urea nitrogen was $19 \mathrm{mgm}$. per $100 \mathrm{cc}$. and the fasting blood sugar 88 mgm. per 100 cc.

At operation several days later the obstruction of the common duct was found to have resulted from dense periductal adhesions with infiltration into the duct wall. After the duct had been dilated a " $T$ " tube was introduced to keep it patulous. The patient made an uneventful recovery and was discharged twenty-four days after operation. The serum calcium on the day after operation was $10.0 \mathrm{mgm}$. per $100 \mathrm{cc}$. and on the day of removal of the " $\mathrm{T}$ " tube it was $10.1 \mathrm{mgm}$. The data from the bile collected from this patient are given in Table III.

The third patient lived only slightly more than seven days after operation and the bile specimens were collected for only seven consecutive 24 hour periods. The history in brief was as follows: M. R., female, age 21. Admitted to the Service of Dr. Muller at the Hospital of the University of Pennsylvania February 12, 1932, died February 23, 1932.

Since January 1931 she had had attacks of pain in the right upper quadrant which radiated to the back and right scapular area, associated with vomiting. The attacks were always nocturnal and after their subsidence she was left with upper abdominal tenderness which persisted for several days. In the two weeks previous to her admission to the Hospital she had had three attacks during which her skin became yellow. 
The temperature on admission was 99.2 , pulse 88 , respiration 18 . She was deeply jaundiced. The urine contained bilirubin and bile salts but was otherwise negative. The van den Bergh was direct positive, indirect 10.5 units. The icteric index was 100 plus. The bleeding time was 20 seconds and the coagulation time by the Lee-White method was 9 minutes. The blood urea nitrogen was $18 \mathrm{mgm}$. per $100 \mathrm{cc}$.

The operation was done under ether anesthesia. The gallbladder was distended and contained several stones which were removed, after which a cholecystostomy was made. The common duct was greatly distended and the liver somewhat pale. The common duct was incised and three stones were removed from it. Another stone was palpated in the lower end of the duct, and required mobilization of this portion of the duct for its removal. The lower incision was closed and a " $\mathrm{T}$ " tube was placed in the common duct through the upper common duct incision. The patient left the operating room in fair condition.

Although she had been prepared with intravenous glucose and calcium chloride for four days previous to operation, she began to ooze blood from the wound on the night of operation. She was immediately transfused with 500 cc. of blood and this was repeated on the succeeding day. Notwithstanding vigorous therapy this oozing continued and the patient died on the 8th day after operation.

TABLE IV

The liver bile obtained after release of common duct obstruction due to a stone (Patient M. R.)

\begin{tabular}{|c|c|c|c|c|c|c|c|c|c|}
\hline \multirow{3}{*}{$\begin{array}{l}\text { Days } \\
\text { after } \\
\text { oper- } \\
\text { ation }\end{array}$} & \multicolumn{9}{|c|}{ Bile } \\
\hline & \multirow{2}{*}{ Volume } & \multicolumn{2}{|c|}{ Base } & \multicolumn{2}{|c|}{ Calcium } & \multicolumn{2}{|c|}{ Chloride } & \multicolumn{2}{|c|}{ Bile salts } \\
\hline & & $\begin{array}{l}\text { Concen- } \\
\text { tration }\end{array}$ & Total & $\begin{array}{l}\text { Concen- } \\
\text { tration }\end{array}$ & Total & $\begin{array}{l}\text { Concen- } \\
\text { tration }\end{array}$ & Total & $\begin{array}{l}\text { Concen- } \\
\text { tration }\end{array}$ & Total \\
\hline & $c c$. & $\begin{array}{l}\text { m. Eq. } \\
\text { per liter }\end{array}$ & m. Eq. & $\begin{array}{l}\text { m. Eq. } \\
\text { per liter }\end{array}$ & m. Eq. & $\begin{array}{l}\text { m. Eq. } \\
\text { per liter }\end{array}$ & m. Eq. & $\begin{array}{l}\text { m. Eq. } \\
\text { per liter }\end{array}$ & m. Eq. \\
\hline $\begin{array}{l}1 \\
2 \\
3 \\
4 \\
5 \\
6 \\
7\end{array}$ & $\begin{array}{r}155 \\
250 \\
150 \\
100 \\
50 \\
50 \\
60\end{array}$ & 159 & 24.6 & $\begin{array}{l}3.7 \\
3.2 \\
3.1 \\
2.7 \\
2.2 \\
2.4 \\
2.2\end{array}$ & $\begin{array}{l}0.6 \\
0.8 \\
0.5 \\
0.3 \\
0.1 \\
0.1 \\
0.1\end{array}$ & $\begin{array}{l}112.9 \\
124.3 \\
127.7 \\
131.7 \\
143.9 \\
154.9 \\
143.6\end{array}$ & $\begin{array}{r}17.5 \\
31.1 \\
19.2 \\
13.2 \\
7.2 \\
7.7 \\
8.6\end{array}$ & $\begin{array}{l}00.0 \\
00.0 \\
00.0 \\
00.0 \\
00.0 \\
00.0 \\
00.0\end{array}$ & $\begin{array}{l}00.0 \\
00.0 \\
00.0 \\
00.0 \\
00.0 \\
00.0 \\
00.0\end{array}$ \\
\hline
\end{tabular}

The data on the bile obtained from this patient are given in Table IV. The total base was measured on only two specimens. The calcium concentrations are low while the chloride concentrations are high. Indeed, the chloride concentration increased daily reaching a level sufficiently high to account for nearly the entire total base. Bile salts, as determined by the Gregory-Pascoe reaction (9), were never found.

Undoubtedly the liver was profoundly damaged as evidenced by the very small amount of bile which was collected, while no evidence was obtained that bile was passing into the duodenum.

\section{DISCUSSION}

There have been numerous studies of various aspects of bile secretion in animals. The recent study of Greene, Walters and Fredrickson (4) 
of nine patients with biliary tract fistulae offers the only other group of human studies besides our own recently reported. In the study by Greene and his associates the bile was collected from the gallbladder or common bile duct. They referred to the fact that a few single or very small groups of cases have been reported where certain constituents of the bile were studied after drainage of the gallbladder or common bile duct. It would be better if the specimens collected from the common duct and from the gallbladder were kept separate, since bile passing through the gallbladder is altered in its composition. This separation was made in the cases in Tables II, III and IV.

The study of human liver bile must of necessity be confined to patients whose common bile duct has been drained because of biliary tract disease. It is not possible to be sure in each instance that the total bile excretion is being collected. Even when one can be certain of this, inferences from the changes in liver bile subsequent to complete external drainage must be drawn with due consideration of the fact that the conditions surrounding the experiment are not normal, for there occurs the complete diversion of bile from the intestine preventing the reabsorption of such materials as have an enterohepatic circulation. It would be ideal to have a complete fistula and a method whereby the bile could be returned to the intestine as in the method devised by McMaster and Elman (11) for the dog. We have attempted to approach this condition by occasionally returning the liver bile to the duodenum after the insertion of a Jutte tube, but this has not as yet been done in any of the cases on which we have made chemical studies.

It is accepted by all workers in this field that the amount of bile excreted by the liver of man and dog may vary greatly from day to day. Although in the studies reported in this paper the total excretion of bile undoubtedly was only rarely obtained, the data show a wide variation even in periods when we believed that little if any bile was entering the duodenum. We have obtained no evidence which would indicate that the amount of bile collected tended to be directly related to the fluid intake of the patient.

The findings relative to total base are in most instances in close agreement with those obtained from hepatic bile of the dog. In two instances the total base was very low, but in the majority of instances the total base concentration was comparable to that of serum. There is no evidence from these studies that total base concentration varied inversely with the amount of bile excreted. Indeed, the evidence is in favor of a relatively constant total base concentration, regardless of the amount of bile flow. The major part of the base is probably sodium. The total amount of base lost in a 24 hour period tends to be proportional to the amount of bile collected. However, the amount of base lost per day is relatively small, the total lost in nine days in Case I being 903.3 m.Eq. (20.8 grams Na). This is approximately the amount of sodium that is excreted normally in the 
urine in a similar period and about one-half the amount, when calculated per day, that Sherman (12) gives as the maximum in an American dietary.

The calcium lost in the collected bile is of course included in the total base. The calcium fraction of this is small, the total amount lost over the 26 day period in Case I being $69 \mathrm{~m} . \mathrm{Eq}$. (1.38 gram Ca). The loss of calcium varied with the amount of bile collected. As a rule, it increased in those cases which survived even though the amount of bile collected did not increase; for there was a tendency for the calcium concentration to increase in the later period of the collection. There was no constant correlation between the calcium concentration of the serum and of the bile. The tendency toward the higher concentration in the later period of drainage may have been related to the calcium of the diet since in the earlier periods the patient received only saline and glucose by a continuous intravenous drip while after the first 5 or 6 days fluids and food were given by mouth.

The chloride concentration in the first specimen of hepatic bile obtained after the release of the obstruction was in every instance at or above the serum level of chloride. In the patients who recovered, the bile at the time of removal of the " $T$ " tube had a chloride concentration at or below the serum level while the chloride concentration of the bile from the patients who died was often considerably above blood level. Indeed, these findings in the 18 cases studied were consistent enough to suggest that the determination of the chloride concentration of the bile may be of some prognostic importance. Greene, Walters and Fredrickson (4) found that the chloride concentration of fistula bile was slightly greater than that of blood serum, although a study of their data suggests that several of their cases showed a tendency similar to that described here. They, however, did not report on the final outcome of their cases, hence satisfactory comparisons cannot be made.

Case I lost $1437.3 \mathrm{~m}$.Eq. of chloride ( 51 grams $\mathrm{Cl}$ ) over a 26 day period. This is approximately the amount found in an average dietary over a similar period.

The bile salt concentrations were the most consistent findings in this study. These cases differ from the group studied by Greene, Walters and Fredrickson (4) in that in every instance in our cases prior to operation there was complete common duct obstruction. In the incomplete obstructions these authors found a reduction in both the concentration and the total output of bile salts. Recovery was, however, rapid. In the more severe obstructions they found that both the concentration and the total output of bile acids were markedly reduced and remained so for the period of study.

In our group of complete obstructions, bile salts were not present in any case in the first specimens obtained. As a rule from one to four weeks passed before bile salts, as evidenced by the Gregory-Pascoe reaction, were present. Greene and his associates used the Aldrich-Bledsoe method (13) 
for the determination of bile salts, a method which may give the characteristic response with other substances normally present in bile. It is, therefore, probable that with their method the response will be obtained earlier and give concentrations in excess of those which we have found using a method which we believe to be more specific for bile salts.

Our findings with regard to bile salts are also in general agreement with those of Smyth and Whipple (14), Brakefield and Schmidt (15), and Snell, Greene and Rowntree (16). From our studies which in nine instances were conducted for longer periods than any others reported, we cannot but conclude that if the " $\mathrm{T}$ " tube is placed in the common duct with the expectation of letting it remain until the liver bile has become normal, the surgeon rarely attains his objective.

In every patient a definite attempt was made to maintain an adequate fluid balance. Fluids were given by various routes. The one which was used in most instances was the intravenous route, the fluid being given by a slow, continuous intravenous drip. Sodium chloride (150 m.Eq. per liter) to which was added sufficient glucose to make a 10 per cent solution was the fluid most frequently used. The amount administered was varied daily depending on the total measured loss of fluid to which was added from 500 to $1500 \mathrm{cc}$. for the insensible loss.

After the patients were able to receive food by mouth, they were given a high carbohydrate, low fat diet containing an adequate amount of protein. Fluids were given by mouth in amounts sufficient to maintain an adequate fluid balance or in addition by intravenous infusions of saline.

If the fluid and salt requirements are adequately supplied during the period when fluids and food cannot be given by mouth, the fluid and salt lost in the bile in cases of the type presented in this paper should not prove serious. In cases of prolonged total diversion of the biliary flow on the other hand, a serious depletion may result unless care is taken to provide an adequate supply of water and salt. Besides the effect of the fluid and salt loss which occurs when the biliary tract is drained, it is necessary to consider the effect of diversion of the bile on the various intestinal functions in which bile plays a part. In prolonged drainage of the common bile duct the importance of considering the extrahepatic functions of the bile deserves consideration. The inability of the intestine to function normally in the absence of bile is probably an important factor in the progressive asthenia observed in cases of total diversion of the biliary flow.

Whipple (17) has shown that animals with bile fistulae may show a marked loss of the inorganic constituents of the skeleton unless great care is exercised with respect to their diet. Pancoast and Pendergrass (18) have observed roentgenological evidences of this in the human subject. Schwann (19) nearly a century ago stated that bile was necessary for life and more recently Whipple (17) and Schmidt (20) have expressed substantially the same viewpoint. How little, or how much bile is necessary 
for maintaining normal function is, however, not known; nor do we know how long a period must elapse before detrimental changes can be demonstrated in a patient with complete diversion of flow to an external biliary fistula provided diet, fluid volume and salt metabolism are adequately controlled.

\section{SUM MARY}

Studies of the liver bile after release of an obstruction of the common bile duct in 18 patients are reported. Although the total bile was only rarely obtained the data reveal the composition of liver bile after release of a ductal obstruction. Total base, calcium, chloride and bile salt concentrations tend to vary from day to day. The calcium concentration of such liver bile is usually lower than the plasma level for calcium. The chloride level is usually higher than the plasma level immediately after release of the obstruction, and tends to fall in those patients who recover and to increase in those who die. The bile salts are always absent in the liver bile after the common bile duct has been completely obstructed for a week or more and their reappearance in the liver bile only takes place after a variable, but considerable period. The common duct drainage tube is in our experience frequently removed before the bile salts have reappeared.

The total fluid and salt loss in those patients whose obstruction has been relieved, so that a portion of the bile passes into the intestine, is not great, and it can be adequately compensated for by careful postoperative treatment. In cases where complete diversion of the biliary flow persists this loss may prove alarming.

The detrimental effect of total bile diversion is probably closely bound up with the extrahepatic function of the bile. In all cases where even partial diversion occurs it is important that attention be directed not only to the fluid and salt requirements of the patient but also to appropriate regulation of the diet.

\section{BIBLIOGRAPHY}

1. Wangensteen, O. H., J. A. M. A., 1929, xciii, 1199. Complete External Biliary Fistula.

2. Walters, W., and Parham, D., Surg. Gynec. and Obst., 1922, xxxv, 605. Renal and Hepatic Insufficiency in Obstructive Jaundice.

3. Walters, W., Greene, C. H., and Frederickson, C. H., Ann. Surg., 1930, xci, 686. The Composition of the Bile Following the Relief of Biliary Obstruction.

4. Greene, C. H., Walters, W., and Fredrickson, C. H., J. Clin. Invest., 1931, ix, 295. The Composition of the Bile Following the Relief of Biliary Obstruction.

5. Johnston, C. G., Ravdin, I. S., Austin, J. H., and Morrison, J. L., Am. J. Physiol., 1932, xcix, 648. Studies of Gall-Bladder Function. V. The Absorption of Calcium from the Bile-Free Gall Bladder.

6. Riegel, C., Ravdin, I. S., and Johnston, C. G., Am. J. Physiol., 1932, xcix, 656. Studies of Gall-Bladder Function. VI. The Absorption of Bile Salts and Cholesterol from the Bile-Free Bladder. 
7. Ravdin, I. S., Johnston, C. G., Austin, J. H., and Riegel, C., Am. J. Physiol., 1932, xcix, 638. Studies of Gall-Bladder Function. IV. The Absorption of Chloride from the Bile-Free Gall Bladder.

8. Ravdin, I. S., Johnston, C. G., Riegel, C., and Wright, S. L., Jr., Am. J. Physiol., 1932, c, 317. Studies of Gall-Bladder Function. VII. The Anion-Cation Content of Hepatic and Gall-Bladder Bile.

9. Gregory, R., and Pascoe, T. A., J. Biol. Chem., 1929, Ixxxiii, 35. The Quantitative Determination of Bile Acids by Means of a New Color Reaction and Monochromatic Light.

10. Drury, D. R., J. Exper. Med., 1924, xl, 797. Studies on the Total Bile. VII. Conditions Influencing the Calcium Content of the Bile.

11. McMaster, P. D., and Elman, R., J. Exper. Med., 1925, xli, 513. Studies on Urobilin Physiology and Pathology. II. Derivation of Urobilin. Relation of the Bile to the Presence of Urobilin in the Body.

12. Sherman, H. C., Chemistry of Food and Nutrition. The Macmillan Company, New York, 1926, 3d ed., 271.

13. Aldrich, M., and Bledsoe, M. S., J. Biol. Chem., 1928, lxxvii, 519. Studies in the Metabolism of the Bile. I. A Quantitative Pettenkofer Test Applicable to the Determination of Bile Acids in the Blood.

14. Smyth, F. S., and Whipple, G. H., J. Biol. Chem., 1924, lix, 623. Bile Salt Metabolism. I. Influence of Chloroform and Phosphorus on Bile Fistula Dogs.

15. Brakefield, J. L., and Schmidt, C. L. A., J. Biol. Chem., 1926, lxvii, 523. Studies on the Synthesis and Elimination of Certain Bile Components in Obstructive Jaundice.

16. Snell, A. M., Greene, C. H., and Rowntree, L. G., Arch. Int. Med., 1927, xl, 471. Diseases of the Liver. VII. Further Studies in Experimental Obstructive Jaundice.

17. Whipple, G. H., Physiol. Rev., 1922, ii, 440. The Origin and Significance of the Constituents of the Bile.

18. Pancoast, H. K., and Pendergrass, E., personal communication.

19. Schwann, T. H., Arch. f. Anat. u. Physiol. u. Wissent. Anat. u. Med., 1844, p. 127. Versuche um auszumitteln ob die Galle im Organismus eine für das Leben wesentliche Rolle spielt.

20. Schmidt, C. L. A., Physiol. Rev., 1927, vii, 129. The Extra-Hepatic Functions of Bile. 